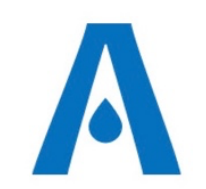

The $I J A$ is a peer-reviewed open-access, electronic journal, freely available without charge to users

Produced by the AquacultureHub non-profit Foundation Sale of IJA papers is strictly forbidden

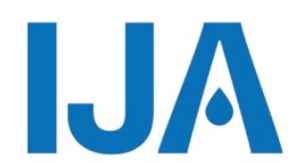

\title{
Benfotiamine counteracts the negative effects of a high dietary carbohydrate on growth and ammonia toxicity resistance in post larval Penaeus monodon
}

\author{
Arnel G. Nudalo', Barry Leonard M. Tumbokon², Augusto E. \\ Serrano, Jr'12* \\ ${ }^{1}$ Institute of Aquaculture, College of Fisheries and Ocean Sciences, University of the \\ Philippines Visayas, Miagao 5023 Iloilo, Philippines
}

${ }^{2}$ National Institute of Molecular Biology and Biotechnology, University of the Philippines Visayas, Miagao 5023 Iloilo, Philippines

Key words: thiamine utilization, dietary carbohydrate, Penaeus monodon, ammonia challenge

\begin{abstract}
The present study aimed to evaluate the effects of high carbohydrate diet in the absence of presence of dietary benfotiamine on growth and immune response against ammonia toxicity (50 mg NH4Cl L-1, average ambient temperature $=27^{\circ} \mathrm{C}, \mathrm{pH} 8.3$ ) of post larval Penaeus monodon. A feeding trial involving three dietary treatments followed by an ammonia toxicity tests and a feed attractability test were conducted separately. During the feeding trial, shrimps were fed three experimental diets, namely, (1) a diet containing $15 \%$ starch (C), (2) a diet with $25 \%$ corn starch (high carbohydrate diet, HC) and (3) a diet containing both $25 \%$ starch supplemented with $0.2 \mathrm{~g} \mathrm{~kg}^{-1}$ benfotiamine (HCB). At the termination of the feeding trial, the shrimps were subjected to ammonia toxicity test to determine the effects of the diets on the immune response of the post larval shrimps. Attractability tests using customized aquaria showed that the HCB diet elicited significantly the highest attractability even after 10 min of feed placement in the feeding chamber. In the feeding trial that lasted for 60 days, results showed that shrimps fed with diet containing HCB exhibited significantly the highest growth rate $(p<0.05)$ among all groups of shrimps in terms of final average body weight (FABW), weight gain (WG), and specific growth rate (SGR); they also exhibited significantly the highest feed intake $(p<0.05)$. Upon challenge of the shrimps with $50 \mathrm{mg} \mathrm{L}^{-1}$ ammonia, shrimps fed with the HCB diet exhibited significantly the highest cumulative survival rate of $60 \%$ after $72 \mathrm{~h}$ while those fed with diet $\mathrm{C}$ and $\mathrm{HC}$ exhibited lower survival rates of $33 \%$ and $40 \%$, respectively, and were not significantly different from each other. In conclusion, benfotiamine enhances attractability of the feed, growth performance and immune response against ammonia toxicity at the level of $0.2 \mathrm{~g} \mathrm{~kg}^{-1}$.
\end{abstract}

\footnotetext{
* Corresponding author. email: serrano.gus@gmail.com
} 


\section{Introduction}

In aquaculture, carbohydrates are the most economical dietary energy source due to their abundance, ready availability and relatively low cost. However, as an energy source, it cannot be fully and efficiently used by aquatic animals compared with poultry and mammals (Wilson and Poe, 1987). High dietary carbohydrate can cause decreased growth rate and other negative effects (Shiau et al., 1991b). Crustaceans have a limited ability to utilize carbohydrate and cannot adapt to high levels of dietary carbohydrate intake (Wang et al., 2016). Consumption of simple sugars in crustaceans can cause negative physiological effect since glucose has a high absorption rate across the digestive tract leading to prolonged hyperglycemia (Shiau et al., 1991; Rosas et al., 2001).

Regardless of the carbohydrate source, it is generally accepted that the carbohydrate requirement for crustaceans is $20-30 \%$ of the total diet, and increased carbohydrate intake can lead to slow growth, low immunity, and a high mortality rate (Wang et al., 2016). Shrimps are diabetic-like animals with high post prandial hemolymph levels of glucose even hours after consumption of a meal containing carbohydrates (Shiau et al., 1991; Rosas et al., 2001). This implies that shrimp needs an energy source, a special requirement linked to the build-up of the new exoskeleton after each molt, or a difficulty to handle the large load that the hemolymph glucose brings (Niu et al., 2012).

Thiamine (vitamin B1) plays a key role in the process of converting carbohydrates into energy (Balakumar et al. 2010). Benfotiamine (pro-vitamin B1) is a lipid-soluble thiamine derivative having much higher bioavailability in human than thiamine (Xie et al., 2014). It is commonly used for the treatment of type II diabetes to improve glucose homeostasis by enhancing glycolysis (Portari et al., 2013) as well as removing excess glycolytic intermediates and reducing hyperglycemic damage (Hammes et al., 2013). In mammals, pro-vitamin B1 stimulates glucose uptake by enhancing the glycolytic and glycogenetic capabilities, increasing mitochondrial glucose oxidation, promoting insulin synthesis, enhancing insulin-stimulated glucose disposal, and increasing the activity of GLUT-2, a glucose transporter (Seh-Hoon et al. 2009; Chung et al. 2014; Fraser et al. 2012). In aquatic animals, information regarding the beneficial effects of benfotiamine is scarce.

Studies on the effects of benfotiamine on the growth performance of shrimps have not been conducted so far. In fish such as the blunt snout bream Megalobrama amblycephala (Xu et al. 2017), it has been demonstrated that the fish fed a high carbohydrate diet supplemented with benfotiamine exhibited higher protein efficiency ratio, nitrogen efficiency ratio and energy retention efficiency. In addition, fish showed relatively high values of whole-body lipid contents, tissue glycogen and lipid contents. In our laboratory, the Nile tilapia fed high carbohydrates diet supplemented with benfotiamine showed significantly better growth than those fish fed high carbohydrate diet without benfotiamine (Lauzon et al. 2019). The present study aimed to evaluate the effects of high carbohydrate diet alone or supplemented with benfotiamine on the growth performance and immune response of the black tiger shrimp.

In addition, we also aimed to determine whether or not it is also an immune-enhancing feed additive. Ammonia and ammonium ion are two of the toxic components in the water medium in aquaculture media since these are produced by the shrimps themselves as a metabolic waste; they are the end products of protein utilization of aquatic animals. The toxicities that result from deteriorating water quality, such as that from ammonia stress, have lethal effects on juvenile shrimp and can increase their susceptibility to pathogens. The toxicity of ammonia plays an important role in the frequent high mortality occurrence during the early stage on shrimp farms (Lu et al., 2017). It is common knowledge that shrimps possess only the innate immune system and not the adaptive immune system; thus, the response to environmental stress such as an elevated ammonia/ammonium ion, or whether to a pathogenic microorganism will elicit similar mechanism of immune response from the shrimp. Thus, an additional objective of determining whether or not dietary benfotiamine enhances the immune response of the black tiger shrimp post larvae was done by challenging it with an elevated ammonia/ammonium level. 


\section{Materials and Methods}

This study was conducted at the University of the Philippines Visayas-National Institute of Molecular Biology and Biotechnology (UPV-NIMBB), Miagao, Iloilo, Philippines.

\section{Experimental Shrimps}

Penaeus monodon (PL20) were purchased from a private hatchery in the nearby town (Guimbal, Iloilo). Prior to the feeding experiment, $P$. monodon post larvae were acclimatized to the experimental conditions and control diet for a week. During the feeding trial, apparent satiation was measured within the first three days of the week and was used as the basis for the feeding rate for the rest of the week, and the same cycle was observed until termination. After acclimatization, $270 \mathrm{P}$. monodon post larvae of similar size (average weight: $0.01 \mathrm{~g}$ ) were randomly distributed among nine indoor plastic containers ( $40 \mathrm{~L}$ volume) at 30 shrimps per container.

\section{Experimental diet preparation}

Three experimental diets were prepared for the first feeding trial namely: (1) control diet containing $15 \%$ corn starch; (2) $25 \%$ corn starch (high carbohydrate diet, HC); and (3) $25 \%$ corn starch (i.e. high carbohydrate diet, HCB) with benfotiamine $\left(0.2 \mathrm{~g} \mathrm{~kg}^{-1}\right.$; Table 1 ). Dry ingredients were mixed first followed by the liquid components; the mixture was thoroughly blended manually with water until a soft dough was obtained. The mixture was steam-cooked and oven-dried at $60^{\circ} \mathrm{C}$ to a moisture content of $10 \%$ or less. An appropriate amount was allocated for proximate analysis. The dry feeds were stored at $4^{\circ} \mathrm{C}$ until use; they were ground and sieved to appropriate size before feeding.

Table 1 Composition of experimental diets to determine the effects of High Carbohydrates and High Carbohydrates supplemented with benfotiamine

\begin{tabular}{|c|c|c|c|}
\hline \multirow[b]{2}{*}{ Feed ingredients } & \multicolumn{3}{|c|}{ Feed composition in $(\mathrm{g})$} \\
\hline & Control & $H C$ & $H C B$ \\
\hline Shrimp (acetes) meal & 200.0 & 200.0 & 200.0 \\
\hline Soybean meal & 200.0 & 200.0 & 200.0 \\
\hline Corn starch & 130.0 & 200.0 & 200.0 \\
\hline Cod liver oil & 40.0 & 40.0 & 40.0 \\
\hline Carboxymethyl cellulose (CMC) & 104.8 & 34.8 & 34.6 \\
\hline Lecithin - Soy $(70 \%)$ & 5.0 & 5.0 & 5.0 \\
\hline Trace mineral premix & 10.0 & 10.0 & 10.0 \\
\hline Vitamin premix & 10.0 & 10.0 & 10.0 \\
\hline Peruvian Fishmeal & 300.0 & 300 & 300 \\
\hline BHT & 0.2 & 0.2 & 0.2 \\
\hline benfotiamine & 0.0 & 0.0 & 0.2 \\
\hline \multirow[t]{3}{*}{ TOTAL } & 1000.0 & 1000.0 & 1000.0 \\
\hline & \multicolumn{3}{|c|}{ Proximate Analysis } \\
\hline & $\begin{array}{r}\text { Control } \\
(\%)\end{array}$ & $H C(\%)$ & $H C B(\%)$ \\
\hline Moisture & 7.44 & 6.71 & 6.67 \\
\hline Crude Protein & 47.50 & 47.09 & 46.30 \\
\hline Crude Lipid & 8.31 & 9.80 & 9.43 \\
\hline Crude Fiber & 2.52 & 2.28 & 2.34 \\
\hline Ash & 13.18 & 14.75 & 14.13 \\
\hline
\end{tabular}

HC : High carbohydrates; HCB : High carbohydrate supplemented with benfotiamine

\section{Diet attractability test}

Six separate attractability tests were conducted using rectangular glass tanks with multiple chambers (Suresh et al.,2011) (Figure 1). Each tank consisted of 3 major chambers (acclimatization chamber, middle chamber, and feeding chamber). The three chambers were separated with a removable glass shutter. The feeding chamber consisted of 5 sub-chambers (only 3 were used in the present experiment), each with a $6 \times 5 \mathrm{~cm}$ access to the feeding chamber. 


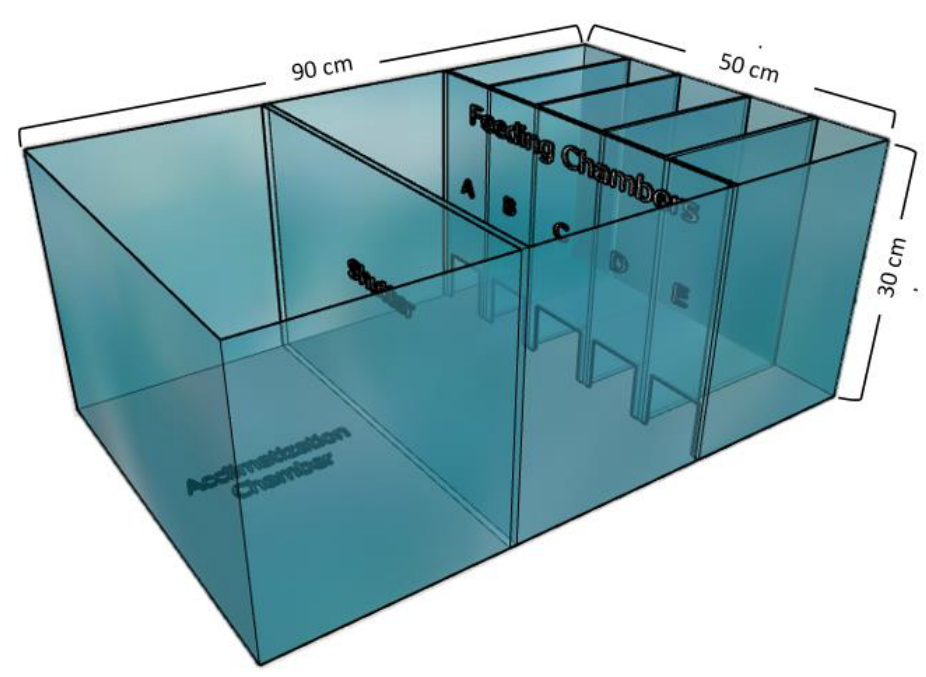

Figure 1 Schematic diagram of the glass tank used for the attractability test

Each glass tank ( $90 \times 50 \times 30 \mathrm{~cm}$ in length, width and height, respectively) consisted of an acclimatization chamber at one end and feeding chambers at the other end separated by a shutter glass that could be lifted to start the test. The tanks were set up in an unlit room that only received diffused fluorescent light, and all assessments were conducted at similar time of the day commencing at $0930 \mathrm{~h}$. Diet attractability was performed on the three experimental diets in three simultaneous runs. Ten randomly selected shrimp was acclimatized for $1 \mathrm{~h}$ after which $2 \mathrm{~g}$ of each experimental diet were placed separately in each of the feeding chambers. Following the lifting of the glass shutter, the number of shrimps that would made it inside each of the feeding chambers was recorded. Diet attractability was expressed as percent of shrimp that were inside a particular feeding chamber containing a particular experimental diet after 1, 5, and 10 min after the shutter was lifted.

\section{Feeding trials}

The feeding trial was conducted in a closed recirculating system consisting of a physical filter (gravel and sand), a biological filter (sterile oyster shells), another physical filter (fiber filter) and a reservoir; the system contained recirculating saltwater (18-20 parts per thousand, ppt) flowing at a rate of $13.3 \mathrm{~L} \mathrm{~h}^{-1}$, and provided with continuous aeration. This study was conducted under controlled laboratory conditions in which 270 healthy shrimp post larvae $(0.01 \mathrm{~g})$ was randomly distributed into 9 tanks. The shrimps were fed the experimental diets 4 times daily until termination. Since the feeding trial involved small and sensitive post larval shrimps, sampling was done every 30 days. At the initial stocking, 270 shrimps $(A B W=0.01 \mathrm{~g})$ were distributed into nine $50-\mathrm{L}$ containers and a separate representative group of shrimps (about 100 shrimps) were weighed separately to obtain the initial weight. The following ranges of water quality parameters were observed during the feeding trial: temperature, $28-30^{\circ} \mathrm{C}$; Salinity, $18-20$ parts per thousand; $\mathrm{pH}-7.8-8.2$ parts per million ( $\mathrm{ppm}$ ); dissolved oxygen, $6.1-6.2 \mathrm{ppm}$; total ammonia- $\mathrm{N}, 0.0-0.1$ ppm; and nitrite, $0.01 \mathrm{ppm}$.

\section{Ammonia challenge test}

Representative shrimps (10 shrimps per container) at the end of the feeding trial (Day 60 ) were used in the ammonia challenge test. The media containing ammonia (50 ppm or $\mathrm{mg}$ ammonia- $\mathrm{N} \mathrm{L}^{-1}$, average ambient temperature $=27^{\circ} \mathrm{C}$; average $\mathrm{pH}=8.3$ ) was prepared by dissolving ammonium chloride $\left(\mathrm{NH}_{4} \mathrm{Cl}\right)$ in sea water at 20 ppt salinity. This concentration of $\mathrm{NH}_{4} \mathrm{Cl}$ was the result of a previous range-finding experiment done in our laboratory. 
Total ammonia- $\mathrm{N}$ was measured using a commercially available water quality kit. Ten shrimps of $P$. monodon juveniles from each container in the feeding trial were placed into corresponding containers containing ammonia (i.e. $50 \mathrm{mg} \mathrm{NH}^{-\mathrm{Cl} \mathrm{L}^{-1}}$ sea water at 20 $\mathrm{ppt}, \mathrm{pH} 8.3$ and average ambient temperature of $27^{\circ} \mathrm{C}$ ). All tanks were provided with sufficient aeration and shrimps were fed with their corresponding diets at $6.5 \%$ body weight daily. Shrimp survival was monitored every 15 min during the first hour, every 30 min during the second hour, every hour after the 4th hour, every $4 \mathrm{~h}$ after the 16 th hour, and every hour on the 24th hour. The shrimp considered dead when immobile and showed no response to touch with a glass rod. Cumulative survival was calculated as follows:

$$
\text { Survival }(\%)=100 * \text { Initial fish count }- \text { dead fish count/initial fish count }
$$

\section{Response parameters}

During the experiment, Weight gain (WG), specific growth rate (SGR), feed intake (FI), feed conversion ratio (FCR) and survival rate (SR), were computed using the following formula:

Weight Gain (WG, g) = Final Average Body Weight (FABW) - Initial Average Body Weight (IABW)

Specific Growth Rate $\left(\mathrm{SGR}, \%\right.$ day $\left.^{-1}\right)=100 *(\log$ of Final Weight $(\mathrm{g})-\log$ of Initial Weight $(\mathrm{g}))$ /No. of Days

Feed Intake $(F I, g)=$ sum of daily feed offered for 60 days $(g)$

Feed Conversion Ratio $(F C R)=$ FI $(g) /$ WG $(g)$

Survival Rate $(\%)=100 *$ Total no. of live Shrimp/Total no. of initial stock

\section{Statistical analyses}

Data (survival rate, weight gain, specific growth rate, and feed conversion ratio, survival rate and attractability test) were presented as mean \pm standard error of the mean (SEM) and were tested for normality using Shapiro-Wilk test and Levene's test for variance homogeneity. Log transformation was used for data that did not pass the two tests; those that passed the test were subjected to one-way Analysis of Variance (ANOVA) at 0.05 alpha using SPSS version 20.0. Percentage data were arc sine-transformed prior to the statistical analyses. Post hoc analyses were done using Duncan's Multiple Range Test (DMRT) to rank the means.

Diet attractability test

\section{Results}

The HCB diet attracted significantly the highest percentage of shrimps even after $10 \mathrm{~min}$ throughout the test period while the $\mathrm{C}$ and $\mathrm{HC}$ group attracted lower percentages and were similar to each other at $5 \mathrm{~min}$. However, at $10 \mathrm{~min}$, the $\mathrm{C}$ diet attracted significantly the lowest percentage of shrimps.

Table 2 Attractability of $P$. monodon to the experimental diets

\begin{tabular}{llll}
\hline & \multicolumn{3}{c}{ Periodic percentage of shrimps \pm SEM } \\
\cline { 2 - 4 } & 1 min & 5 min & 10 min \\
\hline Control & $6.7 \pm 3.3^{\mathbf{b c}}$ & $25.0 \pm 9.2^{\mathbf{b}}$ & $30.0 \pm 0.0^{\mathbf{b}}$ \\
$\mathrm{HC}$ & $3.3 \pm 3.3^{\mathbf{b}}$ & $21.7 \pm 4.8^{\mathbf{b c}}$ & $20.0 \pm 0.0^{\mathbf{c}}$ \\
$\mathrm{HCB}$ & $30 \pm 0.0^{\mathbf{a}}$ & $51.7 \pm 9.5^{\mathbf{a}}$ & $43.0 \pm 3.3^{\mathbf{a}}$ \\
\hline
\end{tabular}

Superscripts indicate significant difference between diets at $(p<0.05)$

$H C$ : high carbohydrate and HCB : high carbohydrate supplemented with benfotiamine 


\section{Feeding trials}

WG of shrimps fed the HCB diet was significantly the highest among the dietary treatments from 30 days to 60 days, followed by the $\mathrm{HC}$ group and $\mathrm{C}$ group in this order and were significantly different from each other (Figure 2 and Table 2).

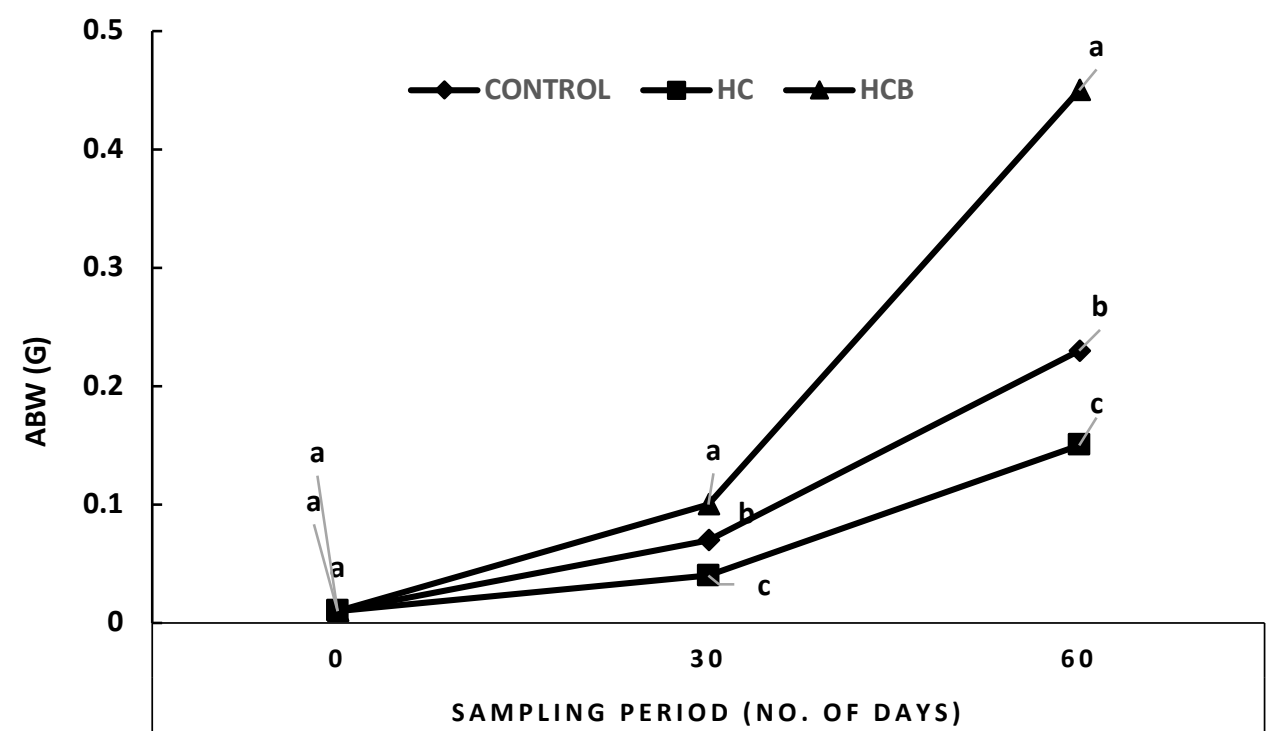

Figure 2 Periodic average body weight (ABW) of shrimp fed with control (C), high carbohydrates diet $(\mathrm{HC})$ and high carbohydrates diet with benfotiamine (HCB). Letters represent significant difference of each treatment at each sampling time.

Growth performance and feed utilization at the termination of the feeding trial are summarized in Table 3. Shrimps fed the HCB diet exhibited the highest growth. FABW, WG, SGR values were significantly the highest in shrimps fed with the HCB diet, followed by the $\mathrm{C}$ and $\mathrm{HC}$ diets in this order, the latter two groups were significantly different from each other $(p<0.05)$.

Shrimps fed with the HCB diet exhibited the best FCR (lowest value), followed by the $\mathrm{HC}$ groups and $\mathrm{C}$ in this order; the latter groups were significantly different from each other.

Table 3. Growth performance and feed utilization of shrimp feed with Control, HC and HCB

\begin{tabular}{lllllll}
\hline & \multicolumn{5}{c}{ Growth performance \pm SEM 1,5 \& 10 min } \\
\cline { 2 - 7 } Diets & IABW & FABW $(g)$ & SGR $(\%)$ & $F I(g)$ & $F C R(g)$ & Surv. (\%) \\
\hline Control & 0.01 & $0.23 \pm 0.003^{\mathbf{b}}$ & $5.44 \pm 0.03^{\mathbf{b}}$ & $0.22 \pm 0.003^{\mathbf{b}}$ & $1.8 \pm 0.00^{\mathbf{b}}$ & $99.99^{\mathbf{a}}$ \\
HC & 0.01 & $0.15 \pm 0.003^{\mathbf{c}}$ & $4.63 \pm 0.04^{\mathbf{c}}$ & $0.14 \pm 0.003^{\mathbf{c}}$ & $1.9 \pm 0.03^{\mathbf{a}}$ & $99.99^{\mathbf{a}}$ \\
HCB & 0.01 & $0.45 \pm 0.006^{\mathbf{a}}$ & $6.56 \pm 0.02^{\mathbf{a}}$ & $0.44 \pm 0.006^{\mathbf{a}}$ & $1.2 \pm 0.00^{\mathbf{c}}$ & $99.99^{\mathbf{a}}$
\end{tabular}

Superscripts indicate significant difference between diets at $(p<0.05)$

$\mathrm{HC}$ : high carbohydrate and HCB : high carbohydrate supplemented with benfotiamine

\section{Ammonia challenge}

Cumulative survival of shrimps in media containing $50 \mathrm{mg} \mathrm{L}^{-1} \mathrm{NH} 4 \mathrm{Cl}$ (dissolved in 20 ppt sea water, $\mathrm{pH} 8.3$, ambient temperature of $27^{\circ} \mathrm{C}$ ) is shown in Figure 3 . At the end of the $72 \mathrm{~h}$ in $50 \mathrm{mg} \mathrm{L}^{-1}$ ammonia, the HCB group exhibited significantly the highest percentage of survival followed by those fed either the $\mathrm{HC}$ or $\mathrm{C}$ group; the latter two groups were not significantly different from each other (Figure 3 and Table 4). 


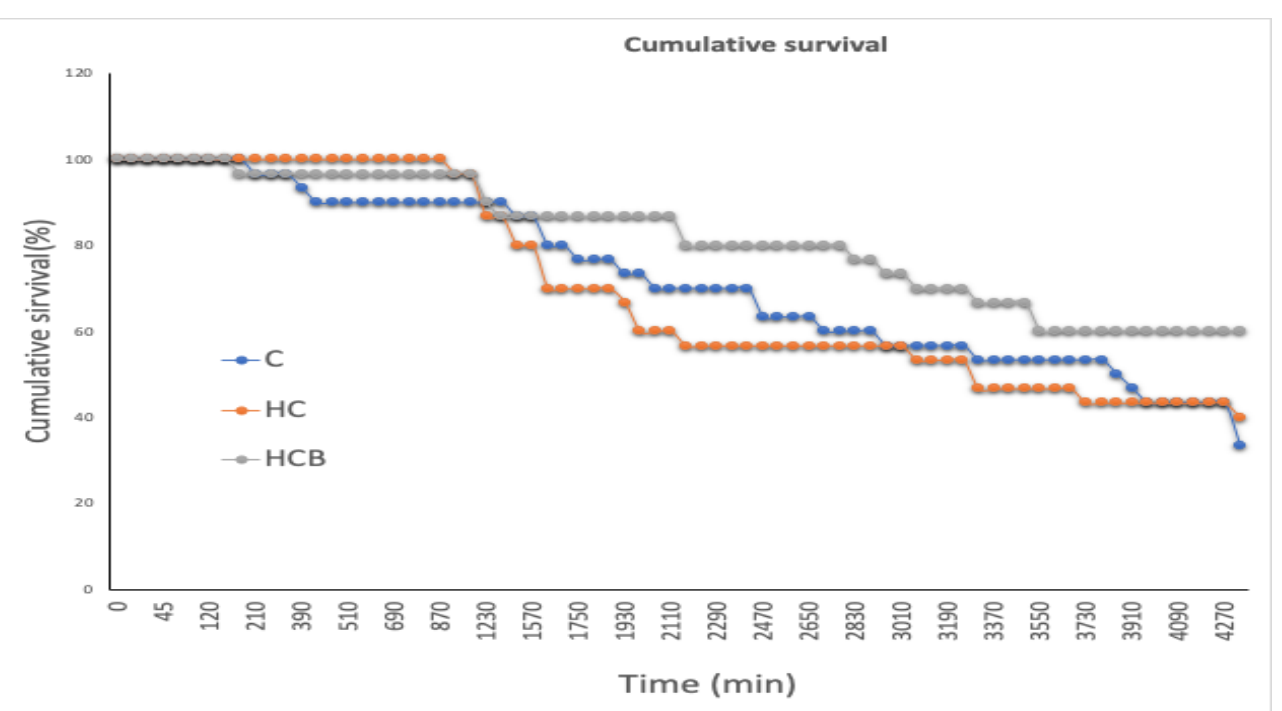

Figure 3 Cumulative survival of shrimp during the 3 days ( $72 \mathrm{~h}) 50 \mathrm{mg} \mathrm{L}^{-1}$ ammonia challenge

Table 4. Survival of shrimp after 3 days ( $72 \mathrm{~h}) 50 \mathrm{mg} \mathrm{L}^{-1}$ ammonia challenge

\begin{tabular}{lc}
\hline & Survival of shrimp \\
\cline { 2 - 2 } Treatments & $(\%)$ \\
\hline Control & $33.33 \pm 3.33 \mathrm{c}$ \\
$\mathrm{HC}$ & $40.33 \pm 5.78 \mathrm{bc}$ \\
$\mathrm{HCB}$ & $60.00 \pm 5.78 \mathrm{a}$ \\
\hline
\end{tabular}

Superscripts indicate significant difference between diets at $(p<0.05)$

\section{Discussion}

Carbohydrates are a source of cheap energy, but the ability of aquatic organisms, including shrimp to utilize it is limited. This is partly due to the lack of ability to digest and regulate plasma glucose concentrations (Wang et al., 2016). The low digestibility of carbohydrates associated with the availability of the enzyme a-amylase, whereas low concentrations of plasma glucose regulation allegedly caused by a deficiency of the hormone insulin (Zainuddin et al., 2018).

Result of the attractability test of the diet in the present study was in agreement with that of the Nile tilapia (Lauzon et al., 2019) in our previous study, in which high carbohydrate diet (HC) elicited lower attractability than did the control (C) diet containing low carbohydrate diet. In contrast, attractability was highest in shrimps fed with the high carbohydrate diet supplemented with benfotiamine (HCB). The attractant effect of (HCB) diet in the present study might be due to the inclusion of dietary benfotiamine; to our knowledge, no previous study has been done except that in our previous study on the Nile tilapia, to determine whether or not benfotiamine is a known attractant to shrimps or insects.

Thiamine is an essential cofactor in most organisms and is required at several stages of anabolic and catabolic intermediary metabolism, such as intracellular glucose metabolism, and is also a modulator of neuronal and neuro-muscular transmission (Beltramo et al., 2008). It can improve glucose homeostasis by blocking three major pathways associated with hyperglycemic damage (Hammes et al., 2003). Benfotiamine is a lipid-soluble thiamine precursor having much higher bioavailability than thiamine (Hammes et al 2003). In the present study, shrimp fed the high carbohydrate diet supplemented with benfotiamine (HCB) showed significantly higher growth performance than those fed with the control (C) and high carbohydrate diet with no benfotiamine supplementation (HC). The final average body weight gain (FABW); specific growth rate (SGR); weight gain (WG) and feed intake were significantly higher in (HCB) than the other 
two diets. The feed conversion ratio was in opposite trend in which the HCB diet resulted in significantly lowest (i.e. most efficient) among other diets. These results showed that the high carbohydrate content was efficiently utilized by supplementing benfotiamine. Survival rate in the present study showed no significant difference among the three dietary groups. These results are in agreement with the previous work on the Nile tilapia that the addition of $20 \mathrm{mg} \mathrm{kg}^{-1}$ supplemental thiamin hydrochloride resulted in a significant growth enhancement (Lauzon et al., 2019). In the blunt snout sea bream, an increase in WG and SGR was observed as a result of feeding the fish with the diet supplemented with benfotiamine (Xu et al., 2018).

Thiamine and it's derivative benfotiamine protects the cells against oxidative stress, suggesting an antioxidant effect of thiamine (Sambon et al., 2019). In this study, shrimp fed the HCB showed significantly higher survival rate compared to either of the control and $\mathrm{HC}$ diet after a $50 \mathrm{mg} \mathrm{L}^{-1}$ ammonia challenge in $72 \mathrm{~h}$. This result was in contrast to the previous study that aimed to determine the ammonia tolerance of $L$. vannamei in $72 \mathrm{~h}$ with a concentration of $32 \mathrm{mg} \mathrm{L}^{-1}$ (Lu et al., 2017). The previous study recorded a mortality rate of $98.6 \%$ after the $72 \mathrm{~h}$ exposure but with no supplementation of benfotiamine. The high survival rate of the present study was probably due to the benfotiamine inclusion in the high carbohydrate diet that enabled protection for the shrimp against oxidative stress. Ammonia in fish is known to induce oxidative injury (Sinha et al., 2015a; 2015b; Hegazi et al., 2010). It is apparent that benfotiamine might have protected the black tiger shrimp against oxidative stress by mitigating ammonia-induced oxidative injury.

In conclusion, incorporation of benfotiamine into the high carbohydrate diet of shrimp significantly enhanced growth performance; attractability of the diet and immune response.

\section{Acknowledgements}

The authors would like to thank the Department of Science and Technology- Accelerated Science and Technology Human Resource Development Program (DOST-ASTHRDP) for the scholarship and thesis grant; University of the Philippines Visayas - Office of the Vice Chancellor for Research and Extension (UPV-OVCRE) for the for the publication grant. The authors are also grateful to Ms. Apple Gray Deallo, Ms. Shellah Dee Canillo, Mr. Vicente Nim and Arly Nim for their technical assistance.

\section{References}

Balakumar, P., Rohilla, A., Krishan, P., Solairaj, P., Thangathirupathi, A., 2010. The multi-faceted therapeutic potential of benfotiamine. Pharmacological Research, 61(6):482488. https://doi.org/10.1016/j.phrs.2010.02.008.

Beltramo, E., Berrone, E., Tarallo, S., Porta, M., 2008. Effects of thiamine and benfotiamine on intracellular glucose metabolism and relevance in the prevention of diabetic complications. Acta Diabetologica, 45:131-141. https://doi.org/10.1007/s00592008-0042-y.

Chung, K.M., Kang, W.Y., Dong, G.K., Hong, H.J., Lee, Y., Han, C.H., 2014. Antidiabetic effects of benfotiamine on an animal model of type 2 diabetes mellitus. Korean Journal Veteronary Research,54:21-26. http://dx.doi.org/10.14405/kjvr.2014.51.1.21.

Fraser, D.A., Hessvik, N.P., Nikolic", N., Aas, V., Hanssen, K.F., Bøhn, S.K., Thoresen, G.H., Rustan, A.C., 2012. Benfotiamine increases glucose oxidation and downregulates NADPH oxidase 4 expression in cultured human myotubes exposed to both normal and high glucose concentrations. Genes and Nutrition,7:459-469. https://doi.org/10.1007/s12263-011-0252-8.

Hammes, H.P., Du, X., Edelstein, D., Taguchi, T., Matsumura, T., Je, Q., Lin, J., Bierhaus, A., Nawroth, P., Hannak, D., Neumaier, M., Bergfeld, T., Giardino, I., Brownlee, M., 2003. Benfotiamine blocks three major pathways of hyperglycemic damage and prevents experimental diabetic retinopathy. American Journal of Ophthalmology, 9:294-299. https://doi.org/10.1016/S0002-9394(03)00802-X. 
Hegazi, N.M., Attia, Z.I., Ashour, O.A., 2010. Oxidative stress and antioxidant enzymes in liver and white muscle of Nile tilapia juveniles in chronic ammonia exposure. Aquatic Toxicology, 99(2): 118-125. https://doi.org/10.1016/j.aquatox.2010.04.007.

Lauzon Q.D, Canillo SD T., Tumbokon BL M., Serrano, AE, Jr., 2019. Effects of High Carbohydrate and Benfotiamine on the Growth and Feed Efficiency of Juvenile Nile Tilapia, Oreochromis niloticus. The Israeli Journal of Aquaculture - Bamidgeh, IJA

Lu, X., Sheng L., Baoxiang C., Xianhong M., Juan S., Ping D., Kun L., Xiaoli S., Dengchun H., Guomin H., Jie K., 2017. Estimation of genetic parameters and genotypeby-environment interactions related to acute ammonia stress in Pacific white shrimp (Litopenaeus vannamei) juveniles at two different salinity levels. Plos One, 12(3): e0173835. https://doi.org/10.1371/journal.pone.0173835.

Niu, J., Lin, H.-Z., Jiang, S.-G., Chen, X., Wu, K.-C., Tian, L.-X., Liu, Y.-J., 2012. Effect of seven carbohydrate sources on juvenile Penaeus monodon growth performance, nutrient utilization efficiency and hepatopancreas enzyme activities of 6-phosphogluconate dehydrogenase, hexokinase and amylase. Animal Feed Science and Technology, 174(1-2): 86-95. https://doi.org/10.1016/j.anifeedsci.2012.03.003.

Portari, G.V., Vannuchi, H., Jordao Jr., A.A., 2013. Liver, plasma and erythrocyte levels of thiamine and its phosphate esters in rats with acute ethanol intoxication: A comparison of thiamine and benfotiamine administration. European Journal of Pharmaceutical Sciences, 48 (4-5): 799-802. https://doi.org/10.1016/j.ejps.2013.01.010.

Sambon, M , Aurore N., Alice D., Julie V., Pierre W., Marianne F., Lucien B., 2019. Thiamine and benfotiamine protect neuroblastoma cells against paraquat and $\beta$-amyloid toxicity by a coenzyme-independent mechanism. Heliyon, 5(5):e01710. https://dx.doi.org/10.1016\%2Fj.heliyon.2019.e01710.

Rosas, C., Lopez, N.,Mercado, P., E. Martinez, E., 2001. Effect of salinity acclimation on oxygen consumption of juveniles of the white shrimp Litopenaeus vannamei. Journal of Crustacean Biology, 21(4):912-922. https://doi.org/10.1163/20021975-99990183.

Seh-Hoon, O., Rafal, P.W., Si-Hyun, B., Houda, D., Jung, Y.M., Liya, P., Brown, A., Petersen, B.E., 2009. Detection of transketolase in bone marrow-derived insulin producing cells: benfotiamine enhances insulin synthesis and glucose metabolism. Stem Cells Development, 18(1):37-45. https://doi.org/10.1089/scd.2007.0255.

Shiau, S. Y., C. C. Kwok, and B. S. Chou. 1991. Optimal dietary-protein level of Penaeus monodon reared in seawater and brackishwater. Nippon Suisan Gakkaishi 57(4):711-716. https://doi.org/10.2331/suisan.57.711.

Sinha, A.K., AbdElgawad, H., Zinta, G., Dasan, A.F., Rasoloniriana, R., Asard, H., Blust, R., Boeck, G.D., 2015a. Nutritional status as the key modulator of antioxidant responses induced by high environmental ammonia and salinity stress in European sea bass (Dicentrarchus labrax). Plos One, 10(8): e0135091. https://doi.org/10.1371/journal.pone.0135091.

Sinha, A.K., AbdElgawad, H., Zinta, G., Dasan, A.F., Rasoloniriana, R., Asard, H., Blust, R., Boeck, G.D., 2015b. High environmental ammonia elicits differential oxidative stress and antioxidant responses in five different organs of a model estuarine teleost (Dicentrarchus labrax). Comparative Biochemistry and Physiology Part C: Toxicology and Pharmacology, 174-175: 21-31. https://doi.org/10.1016/j.cbpc.2015.06.002.

Suresh, A.V., Kumaraguru vasagan, K.P., Nates, S. 2011. Attractability and palatability of protein ingredients of aquatic and terrestrial animal origin and their practical value for blue shrimp, Litopenaeus stylirostris fed diets formulated with high levels of poultry byproduct meal. Aquaculture, 319: 132-140. https://doi.org/10.1016/j.aquaculture.2011.06.039.

Wang, X., Li, E., Chen, L., 2016. A review of carbohydrate nutrition and metabolism in crustaceans. North American Journal of Aquaculture, 78(2): 178-187. https://doi.org/10.1080/15222055.2016.1141129.

Wilson, R. P., Poe, W.E., 1987. Apparent inability of Channel Catfish to utilize dietary monosaccharides and disaccharides as energy-sources. Journal of Nutrition, 117(2):280285. https://doi.org/10.1093/jn/117.2.280. 
Xie, F.F., Cheng, Z.N., Li, S.W., Liu, X.L., Guo, X., Yu, P., Gu, Z.K., 2014. Pharmacokinetic study of benfotiamine and the bioavailability assessment compared to thiamine hydrochloride. Journal of Clinical Pharmacology, 54(6): 688-695. https://doi.org/10.1002/jcph.261.

Xu, C., Liu, W.B., Dai,Y.J., Jiang, G.Z., Wang, B.K., Li, X.F., 2017. Long-term administration of benfotiamine benefits the glucose homeostasis of juvenile blunt snout bream Megalobrama amblycephala fed a high-carbohydrate diet. Aquaculture, 470:74-83. https://doi.org/10.1016/j.aquaculture.2016.12.025.

Zainuddin, H., Aslamyah, S., 2018. Effect of dietary carbohydrate levels and feeding frequencies on growth and carbohydrate digestibility by white shrimp Litopenaeus vannamei under laboratory conditions. Journal of Aquaculture Research and Development 5(6): 1-4. https://doi.org/10.4172/2155-9546.1000274. 